\title{
Crystallized Ammonium Alum and Recovery of Ammonium Alum: Urea DES from Cellulose/DES Solution
}

\author{
Zeena Thamer Salman and Hadi M. A. Abood* \\ Chemistry Department, College of science, Al-Nahrain University, Baghdad, Iraq
}

\begin{tabular}{ll}
\hline \multicolumn{1}{c}{ Article's Information } & Abstract \\
\hline Received: & Recycling and/or recovery of solvent are of important aim in the area of \\
22.02 .2021 & environment or cost. Deep eutectic solvents (DES's) have been widely employed \\
Accepted: & in different research or industrial area. Ammonium alum: urea DES has been \\
07.03 .2021 & researched for possible applications therefore; recovery of this DES is attempted \\
Published: & in this paper. \\
13.03 .2021 & Ammonium alum: urea DES was separated to its constituents by \\
Keywords: & crystallization of ammonium alum from a solution containing cellulose. Urea \\
Deep eutectic solvents & was obtained by evaporation. The crystallization occurs by adding water which \\
Ammonium alum & breaks the hydrogen bonding of DES. Water was added in a 1.25:1 volume ratio \\
Urea & and the resulting crystals and solid materials were examined with ATR-IR and \\
Recovery & X-Ray Diffraction. \\
Recycle & \\
Crystallization & \\
Hydrogen bond & \\
\hline DOI: $10.22401 / A N J S .24 .1 .04$ & \\
*Corresponding author: drha85@yahoo.co.uk & \\
\hline
\end{tabular}

\section{Introduction}

Ionic liquids (IL's), deep eutectic solvents (DES's) and room temperature ionic liquids (RTIL's) are class of solvents with ionic characteristic features similar to molten salt [1]. They share an ease of handling and application in different field of chemistry or industries probably due their low melting point of less than $100{ }^{\circ} \mathrm{C}$, none volatile characterization and low cost. Great efforts have been made to facilitate their applications in catalytic processes, extraction, desulfurization, gas separation, hydrogenation, electronic manufacturing [2].

Deep eutectic solvents (DES) have gained increasing interest of research, as they are less expensive, have an ease of preparation and handling, negligible vapour pressure and are of green solvent offering less environmental impact [3]. The recycling or reuse of solvents is of great important when it comes to evaluate their application in large scale applications and to consider cost and environment effect. Several methods for recovery of ionic liquids including distillation [4], extraction [5], adsorption [6], membrane separation [7], aqueous twophase extraction [7], crystallization [8], and force field separation [9] have been proposed by authors depending on the nature of ionic liquids or their mixtures. The combined design of different methods and process optimization has also been applied for solvent recovery [1, $10,11]$.
DES's are systems formed from a eutectic mixture of Lewis or Brønsted anhydrase acids and bases which can contain a variety of anionic and/or cationic species, in contrast, IL's are formed from systems composed primarily of one type of discrete anion and cation, and although the physical properties of DESs are similar to other ILs, their chemical properties suggest application fields which are significantly different [3]. However, one of the earliest ionic Liquid analogues formed from hydrated metal salts was formed by mixing choline chloride with chromium (III) chloride hexahydrate with the physical properties are characteristic of an ionic liquid [12]. DES like ILs can be separated using for example Robust membrane-based methodology as was employed to separate (choline chloride- $\mathrm{ChCl}$ and ethylene glycol-EG) DES after biomass fractionation[13].However, it is the nature of DES and the process went through would direct the chosen method of separation [10].

Another hydrated salts, like oxyanions, ammonium alum and hydrated ammonium nitrate were also reported to form DES with urea and their characterizations reported to be similar to ionic liquids too [14-16]. These DES containing hydrogen bond donor (HBD) and hydrogen bond acceptor (HBA) compounds formed due to hydrogen bonding between urea and ammonium alum respectively $[3,16]$. Hydrated oxyanions salts: urea deep eutectic liquid was used in different applications such as desulfurization [17], electroplating [18], determining the transition metal 


\section{Al-Nahrain Journal of Science}

ANJS, Vol.24 (1), March, 2021, pp. 20-23

electronic transition behaviors $[19,20]$ and for $\mathrm{CO}_{2}$ capture [21].Furthermore the effect of this DES on several serum human parameters and bacterial growth was also published [22]. A current research for treatment of cellulose with ammonium alum: urea DES (pending for publication by the authors) showed a possibility to separate DES from its mixture with cellulose into its component through crystallization of alum for the first time from such mixture. Therefore, this work will deal with the recovery of the ammonium alum: urea DES from its mixture with cellulose.

\section{Experimental}

Chemical Reagents: All the chemicals of this work were purchased of the highest purity available and used without further purification. The chemicals are micro crystalline cellulose (97\%) of HIMEDIA, ammonium aluminium Sulfate. 12-hydrat (99\%) of Merck and urea (99.5\%) of FLUKA.

Synthesis of Alum Ionic Liquid analogue: Ionic liquid analogue was prepared by mixing 1:5 mole ratio of ammonium aluminium sulfate 12-Hydrate- urea respectively, crushed and heated at $75{ }^{\circ} \mathrm{C}-85^{\circ} \mathrm{C}$ for $3 \mathrm{hrs}$ with continues mechanical stirring until the mixture became a colorless liquid which remained liquids when left to cool at room temperature in a sealed tube [14].

Solid materials were examined by ATR-IR (Bruker Alpha-P ATR FTIR (diamond crystal)) in the range 4000 $\mathrm{cm}^{-1}$ to $400 \mathrm{~cm}^{-1}$ and X-ray Diffractometer (Bruker-X-Ray Diffraction-XRD).

A white suspended solution, scheme $1 \mathrm{~A}$, was obtained from heating $2.5 \mathrm{wt} . \%$ of microcrystalline cellulose(MCC) mixed with ammonium alum: urea DES at $70{ }^{\circ} \mathrm{C}$ for 3 hours in close tube. This was part of an experiment to study the treated cellulose in DES of this work (pending paper by the authors).

A one $\mathrm{ml}$ of the white suspended solution was diluted with $1.25 \mathrm{ml}$ distilled water (D.W.) to reduce the viscosity of the solution and make it easy to separate the cellulose as it settled at the bottom of the tube, scheme $1 \mathrm{~B}$, which was separated by centrifuge.The remaining clear solution was left in close tube for 3 days at room temperature after heating at $70{ }^{\circ} \mathrm{C}$ for $15 \mathrm{~min}$. or for 6 days without heating. Crystals were formed in both cases at small sizes (less than $3 \mathrm{~mm}$ ) and large size (around $5 \mathrm{~mm}$ ) respectively. They were washed with D.W. and dried in open lab atmosphere. The washing solution was mixed with the remaining clear solution and evaporated to dryness forming white solid product.

\section{Result and Discussion}

The obtained crystals from the white suspended mixture of cellulose with ammonium alum: urea DES formed after removing cellulose by centrifuge (detailed in exp. Section above) is shown in Scheme 1, C and D. The crystals were examined by ATR-IR, Figure 1 and X-ray diffraction Figure 2. The white solid material obtained after evaporation and the remaining solution was examined by ATR-IR as shown in Figure 3.
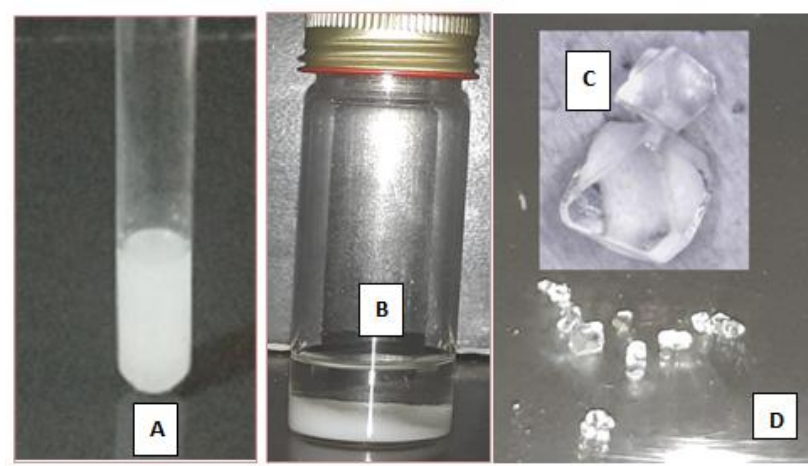

Scheme 1. Ammonium alum: urea DES containing cellulose, suspended white solution (A), diluted (A) with distilled water(B),Large size crystals $(5 \mathrm{~mm})$ from unheated white suspend for 6 days $(\mathrm{C})$, small size crystals around $(3 \mathrm{~mm})$ heated white suspend sample for 3 days (D).

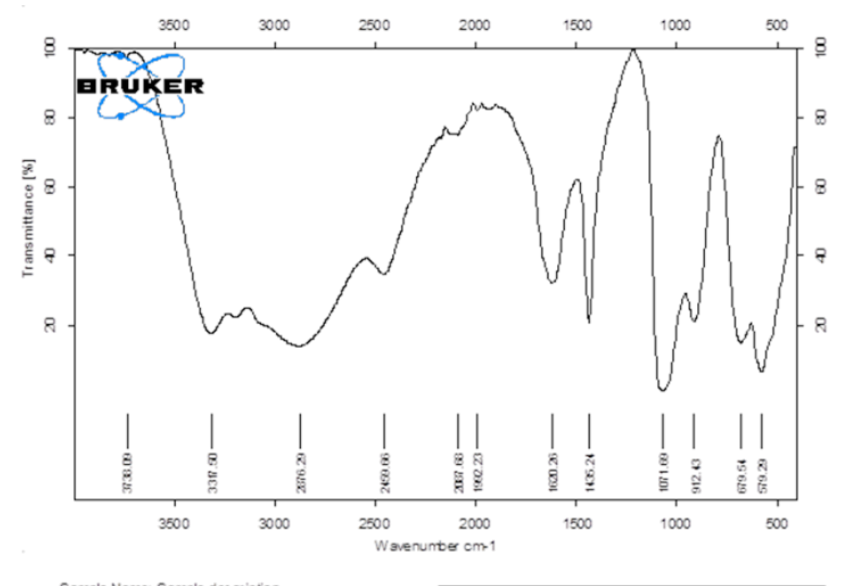

Figure 1. ATR-IR of large or small crystals (Ammonium alum salt)

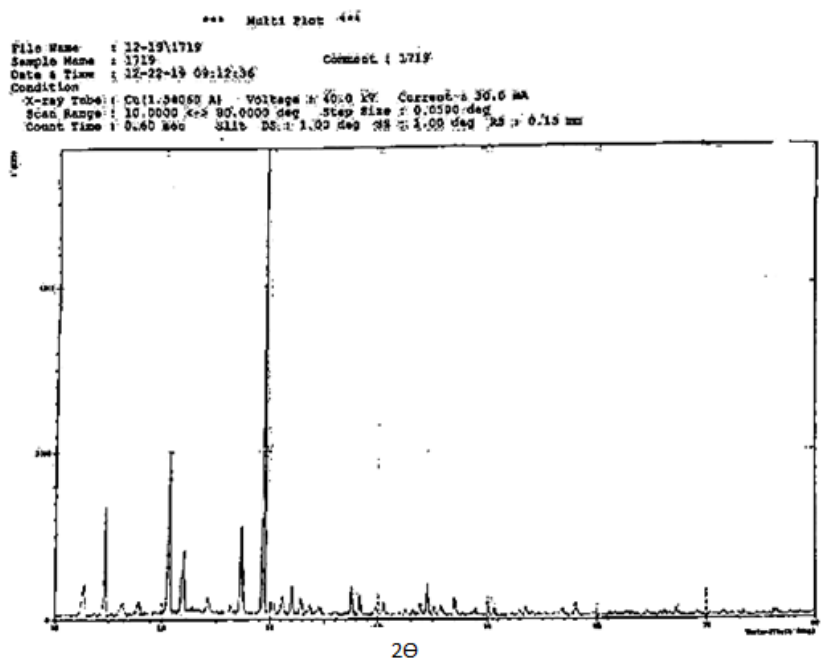

Figure 2. X-ray diffraction pattern of obtained crystals (scheme $1 \mathrm{D}$ ), scanned in the range $20^{\circ}$ to $80^{\circ} 2 \theta$ with 0.01 step time of $0.2 \mathrm{sec}$ at RT. 


\section{Al-Nahrain Journal of Science}

ANJS, Vol.24 (1), March, 2021, pp. 20-23

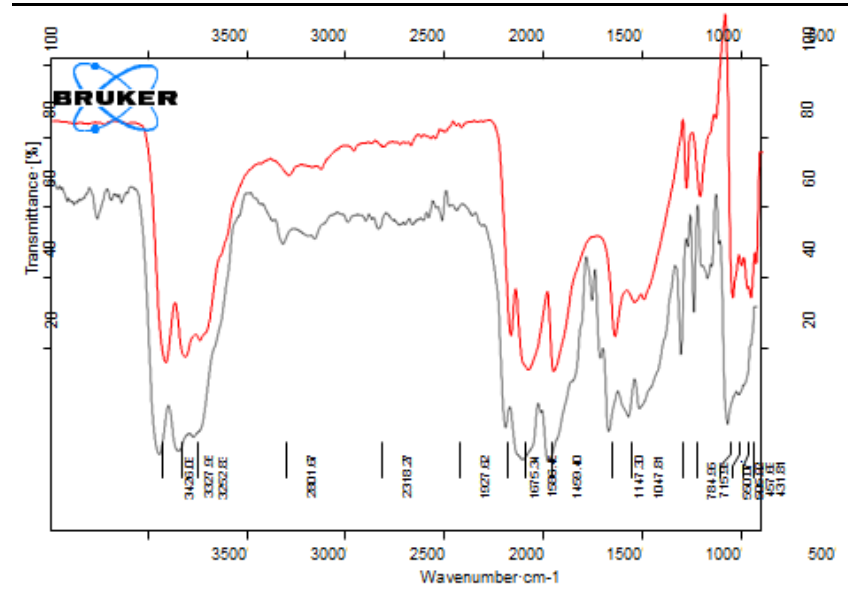

Figure 3. ATR-IR of Urea (black line) and solide white product after evaporation (red line).

The ATR-IR of Figure 1 indicated the characteristic vibrational bands of sulfate at $986 \mathrm{~cm}^{-1}$ and $929 \mathrm{~cm}^{-1}$. Further more characteristic vibration of $\mathrm{Al}-\mathrm{O}$ at $688 \mathrm{~cm}^{-1}$ and the broad bands from $2500 \mathrm{~cm}^{-1}$ to $3500 \mathrm{~cm}^{-1}$ contained water vibration, hydrogen bonding and the amide group stretching vibration together with that vibration at $1665 \mathrm{~cm}^{-1}$. These vibrations indicate that the crystals are ammonium alum. This was further confirmed by X-ray diffraction examination when the resulted data (Figure 2) were indicated by JCPDS international centre for diffraction data (1997) [23] to be ammonium aluminum sulfate 12 hydrate.

The white solid after complete evaporation of the remaining solution was found by ATR-IR (Figure 3) to have similar vibrational bands to the starting urea material used in the preparation of the DES. However, when tested (Benedict's Test) qualitatively for the expected dissolved sugar from cellulose treatment it gave a positive result, yet not quantitatively evaluated.

The separation of the alum or urea was not possible without the addition of D.W. to the white suspended solution. In addition, even when only equivalent amounts of water was added to it the crystals were not formed even after 10 days. This would indicate that water was not only present for dilution as intended in the processes to reduce the viscosity of white suspended solution but also influence the chemical interaction of the DES. This interaction is known as hydrogen bonding between the Lewis acid (ammonium alum) and Lewis base (urea) [3, 12, 24]. Hence, [24] water played an important part in breaking these bonds and separating the DES to its constituents. This is in contrast to the normal crystallization process when super saturation is an important factor [25].

Crystal size seems to be influenced by heating the solution after cellulose removal. The heating reduces the growth of the crystals to smaller sizes than those obtained without heating. This is probably might related to the nucleation effect, as it was reported that during the, nucleation is a critical process having important effect on final product qualities of ammonium alum crystallization, like crystal size distribution and crystal shape which was related to the crystallization process speed [26]. This is in agreement with present work as it was noticed that heating the solution after cellulose separation at $70{ }^{\circ} \mathrm{C}$ for $15 \mathrm{~min}$ accelerate the growth of alum crystals in 3 days faster than without heating (6 days) but gave smaller crystals (compare $3 \mathrm{~mm}$ with $5 \mathrm{~mm}$ respectively, Scheme 1).

It is not believed that present of cellulose would play important role in the crystallization of ammonium alum as the reported work by other workers indicated the role of metal on the crystallization when they present as sulfate salts in the mixture of aluminum sulfate and ammonium sulfate supersaturated solution [27].

The separation of urea and crystallization of ammonium alum make it possible to re-prepare the DES yet with good purity when produced saccharides are removed.

\section{Conclusion}

Recovery of DES can be achieved with crystallization of ammonium alum and evaporating the solution to obtain urea thereby recycling the DES is possible with reasonable purity. The crystallization occurs through hydrogen bond breaking of the DES with added water. Furthermore, ammonium alum: urea DES can also be recycled by separating the cellulose from its mixture and evaporating water from the solution.

\section{References}

[1] Zdanowicz, M.; Wilpiszewska, K. and Spychaj, T.; "Deep eutectic solvents for polysaccharides processing. A review."; Carbohydr Polym. 200, 361-380, 2018.

[2] Tomé, L.; Vanessa, B.; Wanderson, D. and Brett, C.;"Deep eutectic solvents for the production and application of new materials"; Applied Materials Today. 10, 30-50, 2018.

[3] Smith, E.L.; Abbott A.P. and Ryder K.S. ; "Deep eutectic solvents (DESs) and their applications"; Chem Rev. 114(21), 11060-82, 2014.

[4] Weerachanchai, P. and Lee J.-M.J.B.T.; "Recyclability of an ionic liquid for biomass pretreatment"; Bioresource technology. 169, 336-343, 2014.

[5] Blanchard, L. A.; Hancu, D. and Beckman, E. J.; "Green processing using ionic liquids and $\mathrm{CO} 2$ "; Nature. 399(6731), 28-29, 1999.

[6] Zhang, L.; Cao, W.; Alvarez, P. J.; Qu X.; Fu, H.; Zheng, S. and Zhu, D.; "Oxidized template-synthesized mesoporous carbon with $\mathrm{pH}$-dependent adsorption activity: A promising adsorbent for removal of hydrophilic ionic liquid"; Applied Surface Science. 440, 821-829, 2018.

[7] Kröckel, J. and Kragl, U.J.C.E.; "Nanofiltration for the separation of nonvolatile products from solutions containing ionic liquids"; Chemical Engineering \& Technology: Industrial Chemistry-Plant Equipment- 


\section{Al-Nahrain Journal of Science}

ANJS, Vol.24 (1), March, 2021, pp. 20-23

Process Engineering-Biotechnology; 26(11), 11661168, 2003.

[8] Shan, C.; Xingang, L.; Jun, W.; and Changchun, X. U.; "Optimization of parameters for melt crystallization of p-cresol"; Chinese Journal of Chemical Engineering. 20(4). 649-653, 2012.

[9] Hayashi, S.; and H.-O.J.C.L. Hamaguchi; "Discovery of a magnetic ionic liquid [bmim] FeCl4"; Chemistry Letters. 33(12), 1590-1591, 2004.

[10] Zhou, J.; Hong, S.; Zhidan J.; Ziqi Y.; Lin H.; and Xingang L.; "Recovery and purification of ionic liquids from solutions: a review"; RSC Advances. 8(57), 32832-32864, 2018.

[11] Abu-Eishah, S.; "Ionic Liquids Recycling for Reuse"; Ionic Liquids - Classes and Properties. 239-272, 2011.

[12] Abbott, A.; Barron, J.; Ryder, K. and Wilson, D.; "Eutectic-based ionic liquids with metal-containing anions and cations" Chemistry-A European Journal. 13(22), 6495-501, 2007.

[13] Liang, X.; Fu, Y. and Chang, J.; "Effective separation, recovery and recycling of deep eutectic solvent after biomass fractionation with membranebased methodology"; Separation and Purification Technology. 210, 409-416, 2019.

[14] Abood, H.; and Abid, H.; "DSC and TGA Measurements of Room Temperature Ionic Liquids (RTILs) Containing Ammonium Alum or Aluminum Nitrate with Amide Compounds"; Al-Nahrain Journal of Science. 18(2), 56-68, 2015.

[15] Hasan, M.; Abood, H. and Alias, M.; "Investigation of the New Room Temperature Ionic Liquid of Al (NO3) 3.9 H2O with Urea CO (NH2) 2"; Baghdad Science Journal. 13(3), 2016.

[16] Abood, H.; "New ionic liquid made from hydrated aluminum sulfate with amide. Patent", Central Organization for Standardization and Quality, Property division,Iraq, 336, 2012.

[17] Emad, N. and Abood, H,; "Desulfurization of Dibenzothiophene from Model Oil by Aluminum Ammonium Sulfate/Urea (Alum) Ionic Liquid Analogue"; Al-Nahrain Journal of Science. 23(2), 8$17,2020$.

[18] Abood, H. and Ahmed, A.; "Electrodeposition of Antimony from Hydrated Ammonium Aluminum Sulfate-Urea Room Temperature Ionic Liquid"; AlNahrain Journal of Science. 20(4), 7-12, 2017.

[19] Al-Qudsi, Z. and Abood, H.; "The Electronic Transition Behavior Cr (III), Fe (III), Fe (II) and Ni (II), Transition Metal Cations In Ammonium AlumUrea Room Temperature Ionic Liquid"; Al-Nahrain Journal of Science. 16(3), 46-55, 2013.

[20] Hassan, N.; Abood, H. and Alias, M.; "Study the electronic transition behavior of divalent transition metal cations $\mathrm{Co}$ (II), $\mathrm{Ni}$ (II) and $\mathrm{Cu}$ (II) in aluminum nitrate/urea room temperature ionic liquid (1: 1.2)";
International Journal of Science Reseach. 4, 19551961, 2015.

[21] [Abood, H. and Akram, E.; "FTIR Study of Carbon Dioxide Interaction with some Room Temperature Ionic Liquids"; Al-Nahrain Journal of Science. 17(4), 76-85, 2014.

[22] Hasan, B.; Abood, H. and Mohamed, N.; "Effect of Some Aluminum Salts - Amine Ionic Liquids on Several Serum Human Parameters and Bacterial Growth of Klebsiella pneumoniae and Staphylococcus aureus"; Journal of Al-Nahrain University Science. 21(1), 14-22, 2018.

[23] JCPDS, F.J.C.f.D.D.A.r.r.P., Intern. 1: p. 30, 1997.

[24] Abbott, A.; Alabdullah, S.; Al-Murshedi, A. and Ryder, K.; "Bronsted acidity in deep eutectic solvents and ionic liquids"; Faraday Discussions. 206, 365377, 2018.

[25] Mullin, J.; "Crystallization"; Book Elsevier. 2001.

[26] You, S,; Zhang, Y. and Zhang, Y.; "Nucleation of ammonium aluminum sulfate dodecahydrate from unseeded aqueous solution"; Journal of Crystal Growth. 411, 24-29, 2015.

[27] Cheng, W.; Chen, P.; Yu, R. and Ho, W.; "Treating ammonium-rich wastewater with sludge from water treatment plant to produce ammonium alum"; Sustainable Environment Research. 26(2), 63-69, 2016. 